\title{
Light is an effective warning signal in avoidance learning
}

\author{
GEORGE A. CICALA and JULIAN L. AZORLOSA \\ University of Delaware, Newark, Delaware
}

\begin{abstract}
A series of experiments (Jacobs \& LoLordo, 1977, 1980) demonstrated that light onset is an ineffective conditioned aversive stimulus in Sidman avoidance. Jacobs \& LoLordo concluded that light is therefore a poor warning signal in avoidance learning. In the present study, rats were given shuttle avoidance training with either a noise or a light warning signal. Acquisition of the avoidance response was comparable in all groups. This suggests that light and noise stimuli are equally effective warning signals. The implications of these results for models of avoidance learning are discussed.
\end{abstract}

Jacobs and LoLordo $(1977,1980)$ have published a convincing series of experiments demonstrating that light stimuli that have been paired with shock do not produce the enhanced wheel-turn or running-wheel Sidman avoidance responding so often found with a noise warning signal (WS). They interpreted this to mean that light stimuli are not important in the defensive learning system of the rat, and concluded that lights do not arouse a conditioned aversive state when previously paired with shock. For these reasons, they inferred that lights are ineffective WSs in avoidance learning (AL) situations for rats.

This analysis is important because it imposes yet another constraint on the learning process (see Seligman, 1970). Bolles (1970) argued cogently for response specificity in AL situations. What Jacobs and LoLordo (1977, 1980) were suggesting was conditioned stimulus (CS) specificity as well.

Certain issues must be faced before it is concluded that stimulus specificity is the rule in avoidance learning. First, as Jacobs and LoLordo (1980) noted, light onset repeatedly has been demonstrated to be an effective fear elicitor, as indicated by the conditioned emotional response (CER) procedure (see Welker \& Wheatley, 1977). Rescorla (1969) demonstrated conditioned suppression of a barpress response to a light stimulus while using retardation and summation procedures to study conditioned inhibition. However, even if light stimuli were proved to be ineffective conditioned fear elicitors, it is not altogether obvious that conditioned fear is necessary for AL (see Bolles, 1970; Seligman \& Johnston, 1973). Finally, although there have been few experiments that have used light stimuli as WSs in AL, Frontali and Bignami (1973) did find them to produce reliable shuttle AL, and Myers (1964) found that lights produced reliable barpress avoidance.

Although it may be true that the effectiveness of

The authors' mailing address is: Department of Psychology, University of Delaware, Newark, Delaware 19711.
Pavolvian CSs to modulate Sidman avoidance behavior has implications for the acquisition of avoidance responses (ARs) (Rescorla \& Soloman, 1967), the more obvious approach would appear to be the straightforward assessment of the effectiveness of different WSs in a standard AL situation. This is what the present experiment attempted to do. Additionally, two levels of shock were tested to reduce the possibility that the effects obtained would be specific to the shock level selected.

\section{METHOD}

\section{Subjects}

Twenty-four male Wistar rats between 95 and 110 days old and weighing about $350 \mathrm{~g}$ were used in this experiment.

\section{Apparatus}

The experiment used a shuttlebox $(40 \mathrm{~cm}$ long $x 17.5 \mathrm{~cm}$ wide $x 17.5 \mathrm{~cm}$ high) with aluminum walls and a Plexiglas lid. The grid floor consisted of $.23-\mathrm{cm}$ stainless steel rods $1.25 \mathrm{~cm}$ apart, center to center. Each half of the grid floor was mounted on separate axles and connected to a mercury switch. These switches enabled the experimenter to monitor shuttle responding. Two $28-\mathrm{V}$ light bulbs and a $20-\mathrm{cm}$ speaker were located $27.5 \mathrm{~cm}$ above the box. The shuttle apparatus was enclosed in a sound- and light-attenuating box.

The WS was either white noise or light. Readings from a sound meter indicated an average ambient sound level of $42 \mathrm{~dB}$, which increased to $70 \mathrm{~dB}$ upon presentation of the noise WS. The light WS was provided by the two $28-\mathrm{V}$ light bulbs and a $28-\mathrm{V}$ power supply. The unconditioned stimulus (US) was a 150 - or a $100-\mathrm{V}$ ac scrambled shock from a 150 -Kohm fixedimpedance source (Campbell \& Masterson, 1969).

An Apple II computer was programmed to control presentation of the WS, to deliver the US when appropriate, and to monitor all shuttlebox crossings. A different stimulus-control, data-recording program was used for each experimental condition. Permanent copies of these were stored on a floppy disk and accessed via an Apple II disk drive. An Epson printer was interfaced with the computer to produce a permanent record of all shuttle data.

\section{Procedure}

Four equal groups of rats were given shuttle avoidance 
training. Each group received either light or noise as a WS and $100-$ or $150-\mathrm{V}$ shock as a US, yielding a $2 \times 2$ factorial design. Except for presentation of the WS, the subjects were in quiet darkness.

The first of 100 training trials began 1 min after the subject had been placed in the shuttlebox. At the beginning of each trial, the WS was presented. A failure to shuttle within $10 \mathrm{sec}$ resulted in shock onset, after which a shuttle response produced the cotermination of the WS and shock. A shuttle response during the 10-sec WS terminated that stimulus, defined an AR, and prevented shock onset. The intertrial interval (ITI) was $30 \mathrm{sec}$.

\section{RESULTS AND DISCUSSION}

Avoidance responding as a function of 10 trial blocks is shown in Figure 1, according to which all groups apparently acquired the response equally well, reaching asymptote within 50 trials. A $2 \times 2 \times 10$ ANOVA with trial blocks as a repeated measure showed no significant main effect of either WS or shock level, whereas the main effect for trial blocks was highly significant $[F(1,20)=13.75, p<.001]$. There were no significant interactions for these variables. It thus appears that the light stimulus used was an effective WS for rats in a standard shuttle AL situation. Indeed, the light was as effective as the more commonly employed noise WS.

A more careful analysis of Figure 1 suggests one difference between noise- and light-trained groups, a difference that appeared on the first block of trials. To

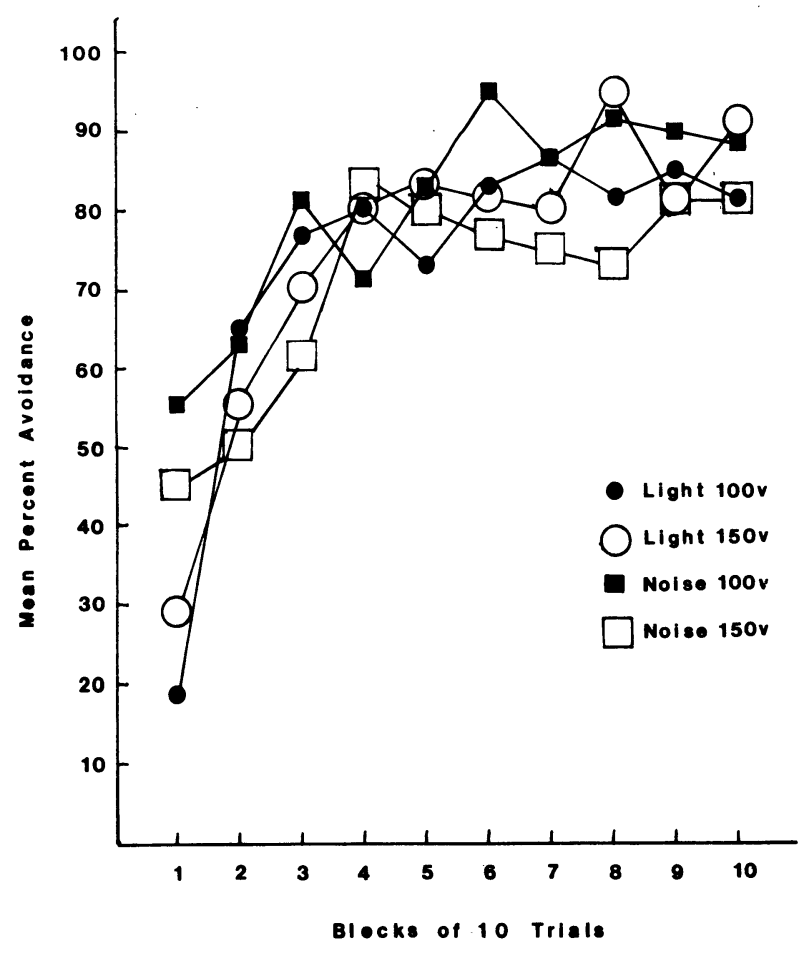

Figure 1. Mean percent avoidance as a function of the trial blocks. evaluate this difference, a $2 \times 2$ ANOVA for the first trial block was performed post hoc. This revealed a significant main effect for WS $[F(1,20)=11.428$, $\mathrm{p}<.01]$. Inspection of Figure 1 suggests an interaction between WS and shock during the first trial block, but this was not significant. An examination of individual subject scores during the first trial block suggested that these differences were due to the spontaneous shuttling during the WS interval by noise-trained subjects. For these subjects, 23 ARs occurred during the first five trials prior to the first avoidance failure and the occurrence of the first shock. This represents a very high rate of spontaneous avoidance, since only 60 ARs were possible. Only 4 of the 12 noise-trained subjects failed to make an AR on the first trial. These data are in sharp contrast with those obtained in the light-trained groups. For these subjects, only 3 ARs occurred prior to the first avoidance failure, and 9 of the 12 rats were shocked on the first trial. Thus, it appears that differences in avoidance during the first trial block were due to either the greater tendency of noise-trained animals to shuttle during the WS or to a heightened tendency of lighttrained animals to freeze during the WS, or to both. This result may suggest important differential motorogenic effects of the stimuli employed. Despite the clear suggestion that these effects are nonassociative, the heightened operant level of responding in noise-trained subjects might have led to superior learning. However, it did not.

The fact that light and noise stimuli are equally effective warning signals in AL would not be predicted by Jacobs and LoLordo (1980). Their finding that lights do not become conditioned fear stimuli when measured on a Sidman baseline appears irrelevant to the effectiveness of lights as warning signals in shuttle AL. This dissociation suggests two possibilities. The Sidman baseline may be insensitive to the fear elicited by conditioned light stimuli, or fear of the warning signal is not necessary for the acquisition of shuttle avoidance. Support for the first possibility is suggested by the finding of Rescorla (1969) and Welker and Wheatley (1977), who showed barpress suppression when light was used as a CS. If it is safe to conclude that light stimuli do elicit fear, this may argue against the second possibility. If light stimuli are effective conditioned fear elicitors, it is reasonable to assume that such stimuli would elicit fear in the AL situation. Furthermore, if WS fear is necessary for $\mathrm{AL}$, successful $\mathrm{AL}$ by lighttrained subjects in the present study is understandable. Thus, the present results suggest that the inclusion of WS specificity in models of AL may be premature.

\section{REFERENCES}

Bolles, R. C. (1970). Species-specific defense reactions and avoidance learning. Psychological Review, 77, 32-48.

Campbell, B. A., \& Masterson, F. A. (1969). Psychophysics of punishment. In B. A. Campbell \& R. M. Church (Eds.), 
Punishment and aversive behavior (pp. 3-42). New York: Appleton-Century-Crofts.

Frontali, M., \& Bignami, G. (1973). Go-no go avoidance discrimination in rats with simple "go" and compound "no go" signals: Stimulus modality and stimulus intensity. Animal Learning \& Behavior, 1, 21-24.

JACOBs, W. J., \& LoLoRdo, V. M. (1977). The sensory basis of avoidance responding in the rat. Learning and Motivation, 8, 448-466.

JAcoBs, W. J., \& LoLordo, V. M. (1980). Constraints on Pavlovian aversive conditioning: Implications for avoidance learning in the rat. Learning and Motivation, 11, $427-455$.

Myers, A. K. (1964). Discriminated operant avoidance learning in Wistar and G-4 rats as a function of type of warning stimulus. Journal of Comparative and Physiological Psychology, 58, 453-455.

Rescorla, R. A. (1969). Conditioned inhibition of fear resulting from negative CS-US contingencies. Journal of Comparative and Physiological Psychology, 67, 504-509.

Rescorla, R. A., \& Soloman, R. L. (1967). Two-process learning theory: Relationships between Pavlovian conditioning and instrumental learning. Psychological Review, 74, 151-181.

Seligman, M. E. P. (1970). On the generality of the laws of learning. Psychological Review, 77, 406-418.

Seligman, M. E. P., \& Johnston, J. (1973). A cognitive theory of avoidance learning. In F. J. McGuigan \& D. B. Lumsden (Eds.), Contemporary approaches to conditioning and learning. New York: Wiley.

Welker, R. L., \& Wheatley, K. L. (1977). Differential acquisition of conditioned suppression in rats with increased and decreased luminance levels as CS + S. Learning and Motivation, 8, 247-262.

(Manuscript received for publication September 30, 1983.) 